Correction

\title{
Correction: Juan, A.A.; Mendez, C.A.; Faulin, J.; de Armas, J.; Grasman, S.E. Electric Vehicles in Logistics and Transportation: A Survey on Emerging Environmental, Strategic, and Operational Challenges. Energies 2016, 9, 86
}

\author{
Angel Alejandro Juan ${ }^{1, *}$, Carlos Alberto Mendez ${ }^{2}$, Javier Faulin ${ }^{3}$, Jesica de Armas ${ }^{1}$ and \\ Scott Erwin Grasman ${ }^{4}$ \\ 1 Computer Science Department, Internet Interdisciplinary Institute, Open University of Catalonia, 08018 \\ Barcelona, Spain; jde_armasa@uoc.edu \\ 2 Instituto de Desarrollo Tecnológico para la Industria Química, Universidad Nacional del Litoral, \\ CONICET, 3000 Santa Fe, Argentina; cmendez@intec.unl.edu.ar \\ 3 Statistics and Operations Research Department, Public University of Navarre, 31006 Pamplona, Spain; \\ javier.faulin@unavarra.es \\ 4 Industrial and Systems Engineering, Rochester Institute of Technology, Rochester, NY 14623, USA; \\ segeie@rit.edu \\ * Correspondence: ajuanp@uoc.edu; Tel.: +34-93-326-3600; Fax: +34-93-356-8822
}

Received: 30 June 2016; Accepted: 30 June 2016; Published: 22 July 2016

The authors wish to make the following changes to the published paper [1]. Changes to the text have been made on pages $7,10,11,12$, and 13 in order to clarify the original source of some of the statements made. Two new references have been added, [35] and [63]. As a consequence, the numbering of other references has changed. The additional references are:

35. Yang, J.; Sun, H. Battery swap station location-routing problem with capacitated electric vehicles. Comput. Oper. Res. 2015, 55, 217-232.

63. Lebeau, P.; de Cauwer, C.; van Mierlo, J.; Macharis, C.; Verbeke, W.; Coosemans, T. Conventional, Hybrid, or Electric Vehicles: Which Technology for an Urban Distribution Centre? Sci. World J. 2015, 2015, doi:10.1155/2015/302867.

We apologize to readers of Energies for any inconvenience caused due to these changes. The manuscript will be updated and the original will remain available on the article webpage.

\section{Reference}

1. Juan, A.A.; Mendez, C.A.; Faulin, J.; de Armas, J.; Grasman, S.E. Electric Vehicles in Logistics and Transportation: A Survey on Emerging Environmental, Strategic, and Operational Challenges. Energies 2016, 9, 86. [CrossRef]

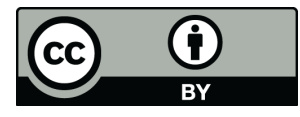

(C) 2016 by the authors; licensee MDPI, Basel, Switzerland. This article is an open access article distributed under the terms and conditions of the Creative Commons Attribution (CC-BY) license (http:/ / creativecommons.org/licenses/by/4.0/). 